Document downloaded from:

http://hdl.handle.net/10251/148460

This paper must be cited as:

Llopis-Lorente, A.; Díez, P.; De La Torre-Paredes, C.; Sanchez, A.; Sancenón Galarza, F.; Aznar, E.; Marcos Martínez, MD.... (2017). Enzyme-Controlled Nanodevice for Acetylcholine-Triggered Cargo Delivery Based on Janus Au-Mesoporous Silica Nanoparticles. Chemistry - A European Journal. 23(18):4276-4281. https://doi.org/10.1002/chem.201700603

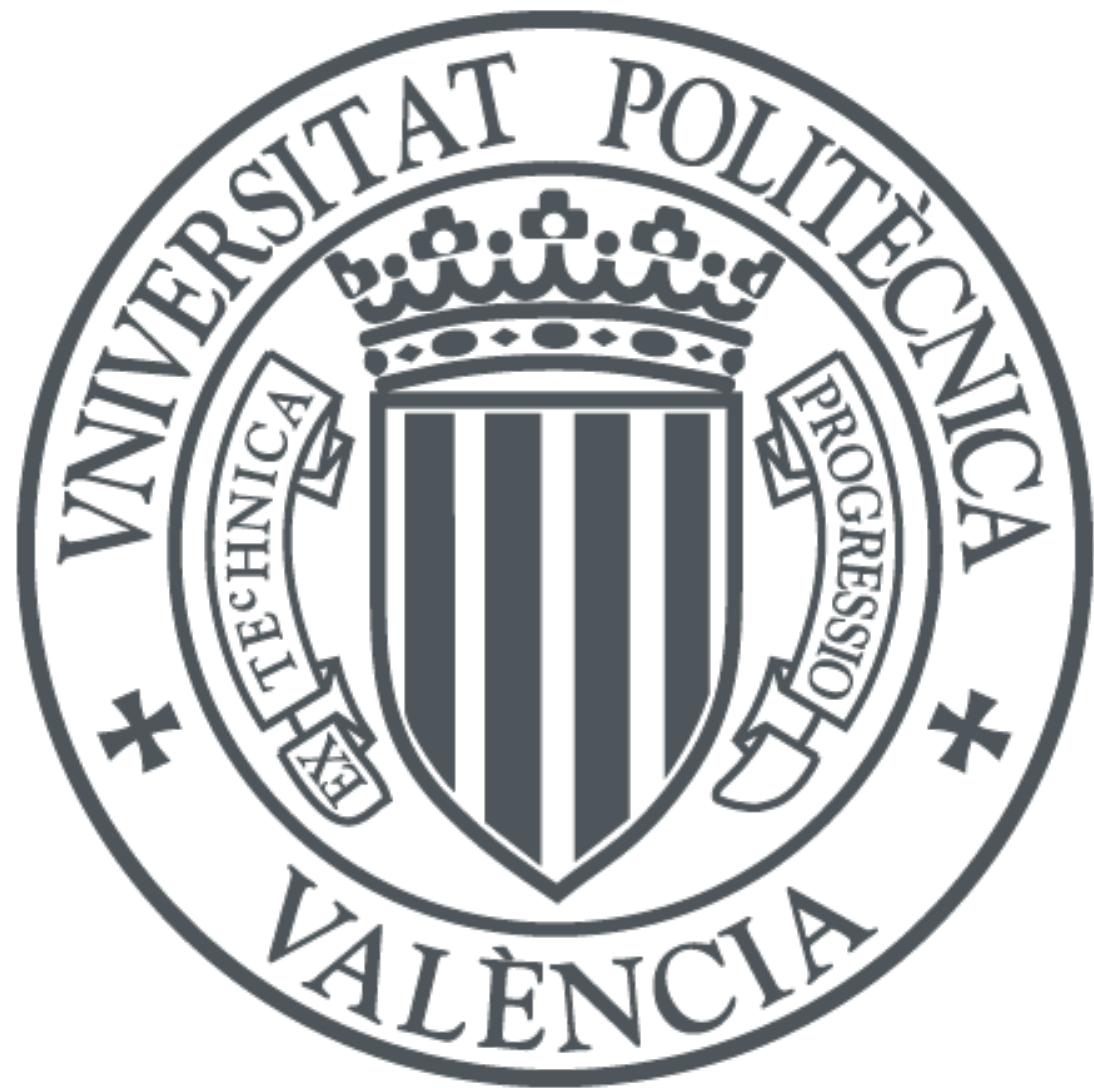

The final publication is available at

https://doi.org/10.1002/chem.201700603

Copyright John Wiley \& Sons

Additional Information

"This is the peer reviewed version of the following article: Llopis-Lorente, Antoni, Paula Díez, Cristina de la Torre, Alfredo Sánchez, Félix Sancenón, Elena Aznar, María D. Marcos, Paloma Martínez-Ruíz, Ramón Martínez-Máñez, and Reynaldo Villalonga. 2017. EnzymeControlled Nanodevice for Acetylcholine-Triggered Cargo Delivery Based on Janus AuMesoporous Silica Nanoparticles. Chemistry - A European Journal 23 (18). Wiley: 427681. doi:10.1002/chem.201700603, which has been published in final form at https://doi.org/10.1002/chem.201700603. This article may be used for non-commercial 


\title{
Enzyme-Controlled Nanodevice for Acetylcholine-Triggered Cargo Delivery Based on Janus Au-Mesoporous Silica
} Nanoparticles

\author{
Antoni Llopis-Lorente, ${ }^{[a, b, c]}$ Paula Díez, ${ }^{[d]}$ Cristina de la Torre, ${ }^{[a, b, c]}$ Alfredo Sánchez, ${ }^{[d, e]}$ Félix \\ Sancenón, ${ }^{[a, b, c]}$ Elena Aznar, ${ }^{[a, b, c]}$ María D. Marcos, ${ }^{[a, b, c]}$ Paloma Martínez-Ruíz, ${ }^{[f]}$ Ramón Martínez- \\ Máñez ${ }^{\star[a, b, c]}$ and Reynaldo Villalonga ${ }^{\star[d, e]}$
}

\begin{abstract}
This work reports a new gated nanodevice for acetylcholine-triggered cargo delivery. We prepared and characterized Janus Au-mesoporous silica nanoparticles functionalized with acetylcholinesterase on the $A u$ face and with supramolecular $\beta$-cyclodextrin:benzimidazole inclusion complexes as caps on the mesoporous silica face. The nanodevice is able to selectively deliver the cargo in the presence of acetylcholine via enzyme-mediated acetylcholine hydrolysis, locally lowering the $\mathrm{pH}$ and opening the supramolecular gate. Given the key role played by $\mathrm{ACh}$ and its relation with PD and other nervous system diseases, we believe that these findings could help design new therapeutic strategies.
\end{abstract}

Acetylcholine (ACh) is an essential neurotransmitter that operates in the central and peripheral nervous system. ${ }^{[1]}$ It acts as a messenger from neurons to muscle cells producing muscle contraction, and is involved in attention, memory and learning. ${ }^{[2]}$ Research has related ACh abnormal levels with neurodegenerative disorders, such as Parkinson's disease (PD) Alzheimer's disease, multiple sclerosis and Huntington's disease. ${ }^{[3]}$ In PD, diminished striatal dopaminergic activity leads to increased $A C h$ release by interneurons. ${ }^{[4]}$ In this context, disruption of the acetylcholine-dopamine balance leads to PD symptoms, which include tremor, hypokinesia, muscular rigidity

[a] A.Llopis-Lorente, Cristina de la Torre, Dr. F. Sancenón, Dr. E. Aznar, Dr. M. D. Marcos, Prof. R. Martínez-Mañez Instituto de Reconocimiento Molecular y Desarrollo Tecnológico (IDM), Unidad Mixta Universidad Politécnica de ValenciaUniversidad de Valencia (Spain)

[b] A.Llopis-Lorente, Cristina de la Torre, Dr. F. Sancenón, Dr. E. Aznar, Dr. M. D. Marcos, Prof. R. Martínez-Máñez Departamento de Química, Universidad Politécnica de Valencia. Camino de Vera s/n, 46022, Valencia (Spain) E-mail:rmaez@qim.upv.es

[c] A.Llopis-Lorente, Cristina de la Torre, Dr. F. Sancenón, Dr. E. Aznar, Dr. M. D. Marcos, Prof. R. Martínez-Mañez CIBER de Bioingeniería, Biomateriales y Nanomedicina (CIBERBBN) (Spain)

[d] P. Díez, Dr. A. Sánchez, Dr. R. Villalonga Department of Analytical Chemistry, Faculty of Chemistry, Complutense University of Madrid, 28040 Madrid (Spain) E-mail: rvillalonga@quim.ucm.es

[e] Dr. A. Sánchez, Dr. R. Villalonga IMDEA Nanoscience Cantoblanco University City, 28049, Madrid (Spain)

[f] Dr. P. Martínez-Ruíz Department of Organic Chemistry I, Faculty of Chemistry, Complutense University of Madrid, 28040 Madrid (Spain)

Supporting information for this article is given via a link at the end of the document. and neuropsychiatric disorders, including depression, fatigue, and speech and memory problems. ${ }^{[5]}$ Drug therapy in PD aims to correct the imbalance between dopamine and $A C h,{ }^{[6]}$ as accomplished by oral administration of: (i) levodopa, a dopamine precursor; ${ }^{[7]}$ (ii) dopamine agonists that activate dopamine receptors; ${ }^{[8]}$ and (iii) anticholinergics, used to lower ACh levels. ${ }^{[9]}$ However, many adverse side effects (e.g. dyskinesia, motor fluctuations, psychosis and drug-resistance) are associated with these drugs and impact PD patients' quality of life. ${ }^{[10]}$ In order to find new ways to treat PD, an appealing approach is to design nanocarriers able to deliver a certain drug in regions with high ACh levels.

From another point of view, much interest has been shown in recent years in the development of stimuli-responsive nanomaterials for drug delivery given their potential application in nanomedicine. ${ }^{[11]}$ Among the various potential nanocarriers, silica mesoporous supports (SMS) are especially appealing because of their unique properties, such as high loading capacity, easy functionalization, low cost and biocompatibility. ${ }^{[12]}$ In addition, one interesting characteristic of SMS is the possibility of functionalizing the external surface with molecular and/or supramolecular ensembles that act as molecular gates. These gated solids show no cargo release, but can deliver the payload in response to certain external stimuli, thus minimizing therapy-derived side effects. In line with this, SMS that are responsive to different stimuli, e.g. light, temperature, magnetic fields, enzymes, DNA, redox reactions and $\mathrm{pH}$, have been developed. ${ }^{[13]}$ However, very few examples of gated SMS that can deliver their cargo in the presence of target small molecules of biological importance have been reported. ${ }^{[13 b]}$

In this area of gated chemistry we recently reported the design of more sophisticated nanodevices for delivery applications based on Janus nanoparticles with $\mathrm{Au}$ and mesoporous silica (MS) on opposite faces. ${ }^{[14]}$ This allows the inclusion of responsive ensembles anchored to the pore outlets of the mesoporous face, and also a "control unit" on the Au face that directs the operation (cargo delivery) of the gated material.

Given the importance of ACh in nervous system diseases such as PD, the need for developing better therapies, and given our interest in designing gated hybrid materials, ${ }^{[15]}$ we report herein the preparation of an acetylcholinesterase-controlled nanodevice based on Janus-type Au-mesoporous silica nanoparticles. Scheme 1 illustrates the design of the system. Enzyme acetylcholinesterase is immobilized on the Au face of the Janus support, which acts as the "control unit". The MS face is loaded with the cargo (e.g. $\left[\mathrm{Ru}(\mathrm{bpy})_{3}\right] \mathrm{Cl}_{2}$ ) and is functionalized with a pH-responsive $\beta$-cyclodextrin $(\beta-C D)$-benzimidazole supramolecular nanovalve. The Au side acts as an "effector" in 
which acetylcholinesterase monitors the presence of overexpressed ACh and induces cargo delivery. In particular, it is expected that the hydrolysis of ACh by the enzyme to give choline and acetic acid will induce a local decrease in $\mathrm{pH}$, which will result in the protonation of benzimidazole, the rupture of $\beta$ CD-benzimidazole ensemble and cargo release. Such a nanodevice may play a double role when reaching regions with high ACh concentrations, such as neuromuscular junctions or the striatum in PD patients: (i) local cargo delivery that would reduce side effects and (ii) lowering $\mathrm{ACh}$ levels, thus acting as anticholinergic agents.

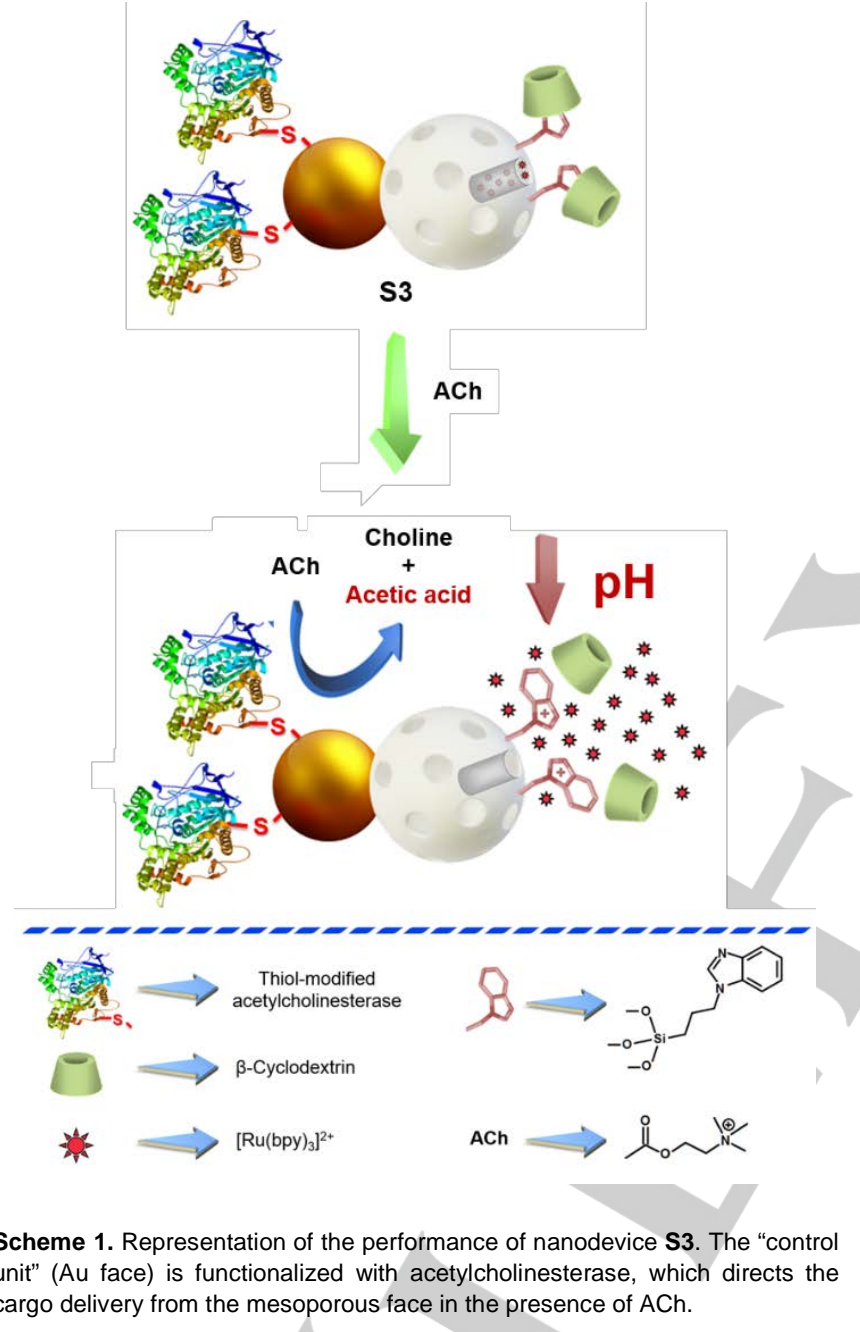

In order to prepare the nanodevice, we first synthesized MS nanoparticles by hydrolysis and condensation of tetraethyl orthosilicate in basic media using $n$-cetyltrimethylammonium bromide as a template. Surfactant removal by calcination yielded the starting mesoporous support (MCM-41). Gold nanoparticles were synthesized by reduction of Au (III) with sodium citrate, according to the Turkevich-Frens method. ${ }^{[16]}$ Then MCM-41 nanoparticles were confined at a Pickering emulsion using paraffin wax to achieve its partial functionalization with (3mercaptopropyl)triethoxysilane, to which Au nanoparticles were attached. Next we dissolved paraffin wax in $\mathrm{CHCl}_{3}$ to finally obtain Janus Au-MS nanoparticles (S1). Afterward, mesoporous scaffold pores were loaded with $\left[\mathrm{Ru}(\mathrm{bpy})_{3}\right] \mathrm{Cl}_{2}$ and the external surface was functionalized with (3-iodopropyl)trimethoxysilane. Then a nucleophilic substitution reaction between the grafted iodopropyl moieties and benzimidazole yielded solid S2. The pores of the $\mathbf{S} 2$ nanoparticles were capped with a $\mathrm{pH}$-sensitive supramolecular nanovalve by stirring the solid with $\beta-C D$ in water, which led to the formation of inclusion complexes between the benzimidazole groups and $\beta$-CD. Finally, acetylcholinesterase, previously modified on its glycosylation chains with thiol groups, ${ }^{[17]}$ was covalently immobilized on the $\mathrm{Au}$ face by incubation in $50 \mathrm{mM}$ sodium phosphate buffer $(\mathrm{pH} 7.5)$ at $0^{\circ} \mathrm{C}$, which resulted in the final nanodevice $\mathrm{S3}$ (see Supporting Information for further details).
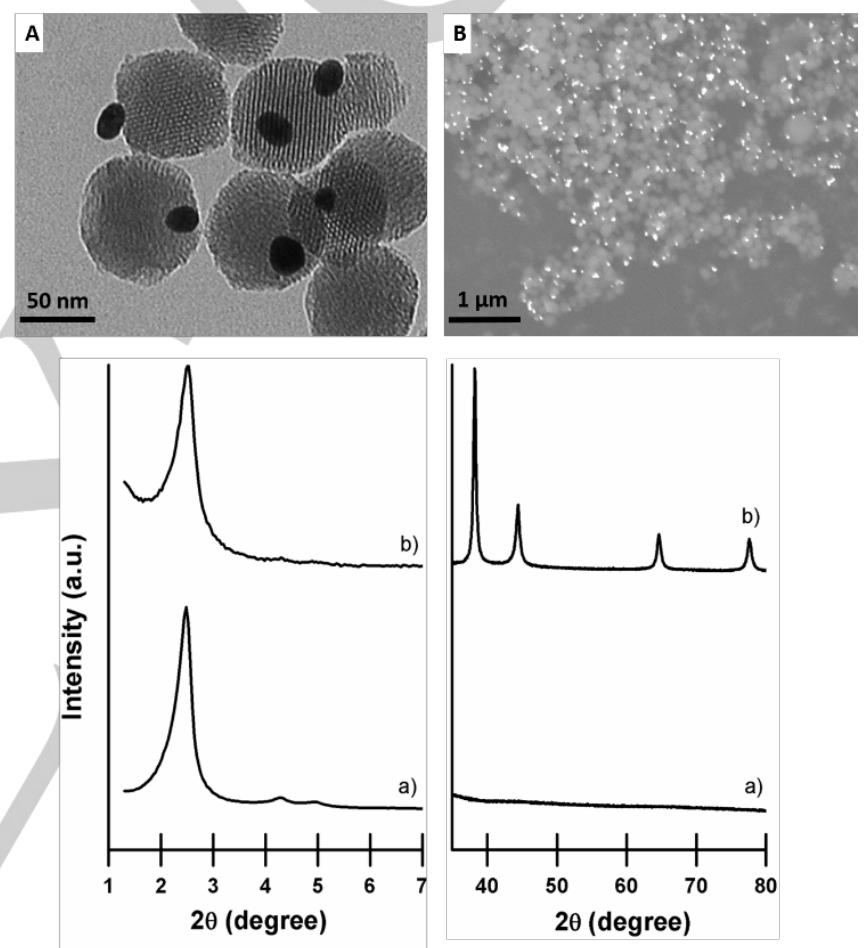

Figure 1. Top: Representative (A) TEM and (B) SEM images of Janus Au-MS nanoparticles (S1) Down: PXRD of (a) calcined MCM-41 and (b) final nanodevice $\mathbf{S} 3$ at low (left) and high (right) angles.

We followed standard procedures to characterize the prepared solids (see Supporting Information). Transmission electron microscopy (TEM) confirmed both the mesoporous morphology of the MCM-41 nanoparticles (average diameter: $70 \pm 15 \mathrm{~nm}$ ) and the presence of $\mathrm{Au}$ nanoparticles (average diameter: $21 \pm 4 \mathrm{~nm}$ ) in Janus colloids (S1, see Figure $1 \mathrm{~A}$ ). Additionally, SEM images of the colloids were also acquired where gold nanoparticles clearly appear as bright dots (see Figure 1B). Powder X-ray diffraction (PXRD), carried out on the starting MCM-41 nanoparticles, showed the (100) low-angle reflection peak that is characteristic of these mesoporous materials. Preservation of the (100) peak in the following solids (S1, S2, S3) (see Figure SI-2) clearly confirmed that the dye 
loading and chemical modifications processes did not damage the 3D mesoporous structure. The diffraction pattern at a high angle for all the Janus colloids showed the cubic gold characteristic (111), (200), (220), and (311) peaks, which confirmed the presence of gold nanocrystals. ${ }^{[18]}$ From thermogravimetric and elemental analyses, we determined the contents of $\left[\mathrm{Ru}(\mathrm{bpy})_{3}\right] \mathrm{Cl}_{2}$ and benzimidazole on $\mathbf{S} 2$ to be $0.162 \mathrm{~g}$ and $0.105 \mathrm{~g}$ per gram of nanoparticles, respectively. For nanodevice S3, we determined the amount of immobilized acetylcholinesterase as $93 \mathrm{U} \cdot \mathrm{g}^{-1}$, that corresponds to $3.4 \mathrm{mg} \mathrm{g}^{-1}$ of S3 (see Figure $\mathrm{SI}-7$ ). We also calculated the BET specific surface values, pore volumes and pores sizes from the $\mathrm{N}_{2}$ adsorption-desorption isotherms (summarized in Table SI-1). The solids were also characterized by FT-IR analysis (see Figure SI-5). Further, dynamic light scattering (DLS) studies under physiological conditions (PBS, $\mathrm{pH}$ 7.5) were carried out on the materials (see Table SI-2). Functionalization with benzimidazole moieties reduced the zeta potential of the nanoparticles S2 (-6.6 mV) compared to calcined MCM-41 ($21.5 \mathrm{mV})$ and Janus colloids $\mathbf{S} 1(-12.5 \mathrm{mV})$. For the final nanodevice S3, the surface charge increased (-14.9) compared to $\mathbf{S} 2$ as a consequence of enzyme functionalization and $\beta$ cyclodextrin capping. In addition, the hydrodynamic diameter for each material was also determined. An increase after each functionalization step was observed which resulted in a hydrodynamic diameter of $195 \mathrm{~nm}$ for the final S3 nanodevice (hydrodynamic diameter for MCM-41, S1 and S2 was 91.2, 141.8 and $164.2 \mathrm{~nm}$ respectively).

In order to test the capacity of the capped Janus nanoparticles to deliver the cargo, we brought S3 to a concentration of $0.9 \mathrm{mg} \cdot \mathrm{mL}^{-1}$ in water at $\mathrm{pH} 7.5\left(20 \mathrm{mM} \mathrm{Na}_{2} \mathrm{SO}_{4}\right)$ in the absence and presence of ACh (1 mM). We took aliquots at scheduled times, centrifuged to remove nanoparticles, and we evaluated cargo release by measuring the emission band of $\left[\mathrm{Ru}(\mathrm{bpy})_{3}\right] \mathrm{Cl}_{2}$ at $595 \mathrm{~nm}\left(\lambda_{\mathrm{exc}}=453 \mathrm{~nm}\right)$. Figure 2 shows the payload delivery kinetics. In the absence of ACh, S3 is tightly capped and dye release is negligible. However, presence of ACh induced pore opening and a subsequent remarkable cargo delivery in under 5 minutes. We attributed the response in the presence of $\mathrm{ACh}$ to the "detection" of this neurotransmitter by acetylcholinesterase (effector) in the "control unit", which triggered cargo release from the MS nanocarrier. Acetylcholinesterase catalyzed the hydrolysis of ACh to choline and acetic acid $\left(\mathrm{pK}_{\mathrm{a}}=4.75\right)$. Acetic acid induced the protonation of benzimidazole groups $\left(\mathrm{pK}_{\mathrm{a}}=5.55\right)^{[19]}$ on the MS face and the dethreading of the supramolecular nanovalve, which finally resulted in cargo delivery. Testing the response of the $\beta$ cyclodextrin-capped solid (without enzyme) in the presence of ACh demonstrated the crucial role played by the enzyme in the "control unit". In this case, no payload delivery took place.

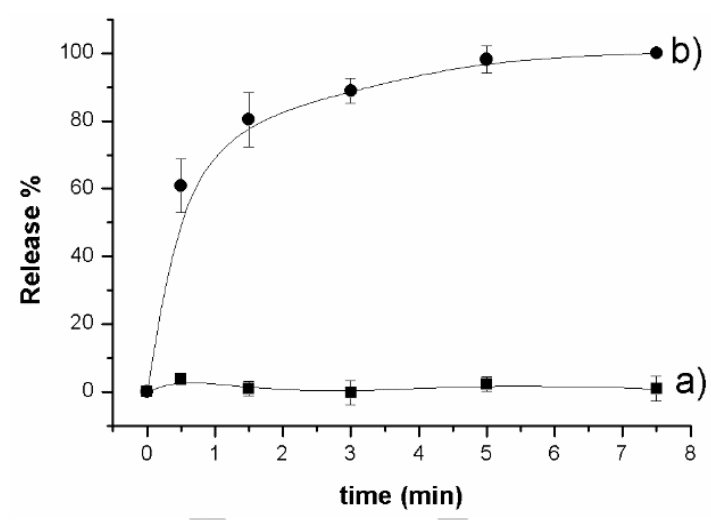

Figure 2. Normalized cargo release from $\mathbf{S 3}$ determined by measuring $\left[\mathrm{Ru}(\mathrm{bpy})_{3}\right] \mathrm{Cl}_{2}$ fluorescence at $595 \mathrm{~nm}\left(\lambda_{\mathrm{exc}}=453 \mathrm{~nm}\right)$ versus time in water at $\mathrm{pH} 7.5\left(20 \mathrm{mM} \mathrm{Na}_{2} \mathrm{SO}_{4}\right)$ in the absence (curve a) and presence (curve b) of ACh $1 \mathrm{mM}$. Error bars from three independent experiments.

The second step tested the response of solid S3 in the presence of some other important neurotransmitters, such as serotonin (5-HT), dopamine (DA), norepinephrine (NE), glycine (Gly), y-aminobutyric acid (GABA), aspartic acid (Asp) and glutamic acid (Glu). Figure 3a shows the release of ruthenium dye upon the addition of these neurotransmitters (1 $\mathrm{mM})$ to suspensions of $\mathbf{S} 3\left(0.9 \mathrm{mg} \cdot \mathrm{mL}^{-1}\right)$. These chemicals were unable to trigger cargo release in $\mathbf{S 3}$, which opened selectively in the presence of $\mathrm{ACh}$.

In another step we studied the response of S3 according to ACh concentration (see the results in Figure $3 b$ ). A linear dye release occurred within the $10^{-5}-10^{-2} \mathrm{~mol} \cdot \mathrm{L}^{-1} \mathrm{ACh}$ concentration range. From the calibration curve, we calculated a limit of detection (LOD) to be $1.5 \times 10^{-5} \mathrm{~mol} \cdot \mathrm{L}^{-1}$. It is noteworthy that S3 did not respond to concentrations lower than $10 \mu \mathrm{M}$. When compared this data with the ACh concentrations found in the body and reported in the literature (see Table SI-4), this suggested that $\mathbf{S} 3$ would remain capped at ACh levels found in human blood $(9 \mathrm{nM}),{ }^{[20]}$ but would release its cargo at regions with higher ACh concentrations. For instance, ACh concentration in synaptic vesicles is estimated to be $100 \mathrm{mM}^{[21]}$ and in neuromuscular junctions and synaptic clefts ACh levels have been reported to be $3-0.5 \mathrm{mM}^{[21]}$ under normal conditions and might increase in PD patients. ${ }^{[4]}$ Although, the $\mathrm{ACh}$ concentration reached just upon presynaptic release is not precisely known, several studies have reported ACh concentrations in the striatum (which is the target region for levodopa and other PD drugs) to be $30-50 \mu \mathrm{M}^{[22]}$. In other brain regions such as the hippocampus and frontal cortex, $A C h$ levels are also higher (ca. 7 and $3.75 \mathrm{mM}$ respectively) ${ }^{[23]}$ suggesting that $\mathbf{S} 3$ would also deliver the cargo in these regions. Despite the fact that the road from these results to the in vivo use of similar nanodevices remains long and uncertain, these results suggested S3 or similar nanodevices could be suitable drug release systems for the treatment of diseases such as PD. 

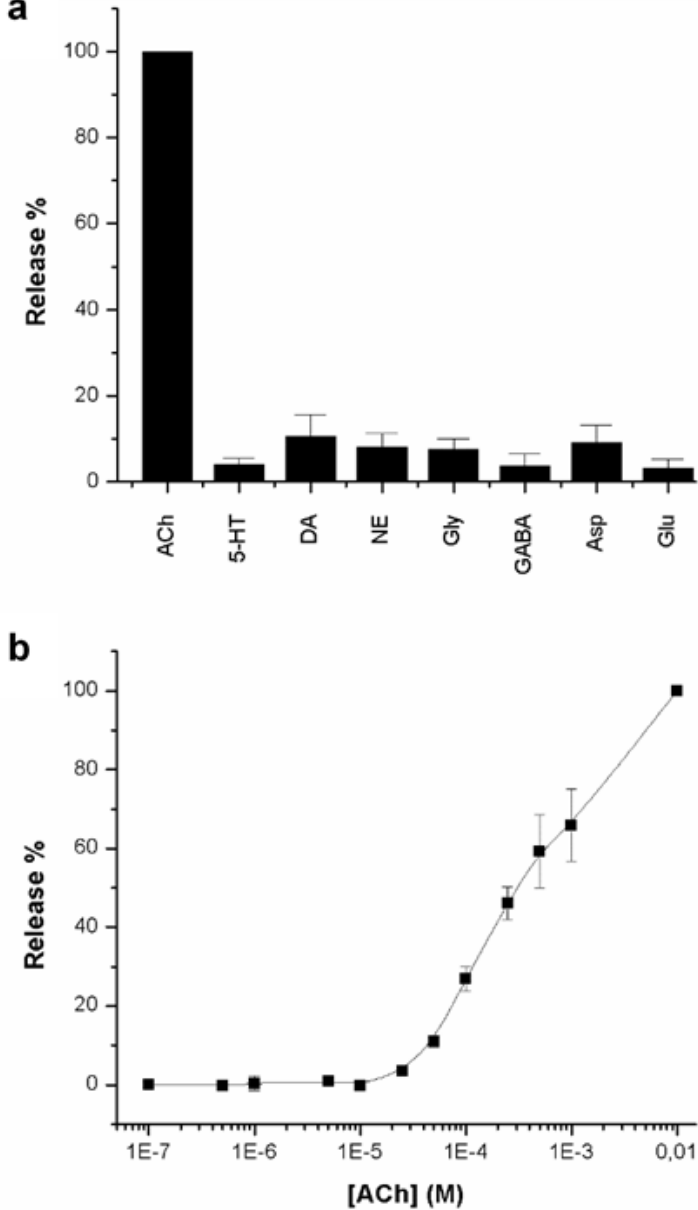

Figure 3. a) Normalized cargo release from $\mathbf{S} 3$ in the presence of different neurotransmitters at $1 \mathrm{mM}$. b) Normalized cargo release after 5 min according to ACh concentration. Error bars from three independent experiments.

We ultimately aimed to demonstrate that the Janus capped system can be used to deliver cargo in the presence of ACh in a biological complex medium. In particular for these experiments, we prepared similar nanoparticles to S3, but loaded with cytotoxic doxorubicin (Doxo) (solid S4, see Supporting Information). We did spectrophotometric studies to calculate the amount of Doxo loaded on $\mathbf{S} 4$ that was found to be $0.035 \mathrm{~g}$ per gram of solid. The release in vitro experiments showed that $\mathbf{S 4}$ (0.9 $\mathrm{mg} \cdot \mathrm{mL}^{-1}$ ) remained capped for at least $24 \mathrm{~h}$, but Doxo release was substantial in the presence of $A C h$ (see Figure $4 A$ ).

Next as proof of concept, we added $100 \mu \mathrm{g} \cdot \mathrm{mL}^{-1}$ of $\mathbf{S} 4$ to the culture media of human cervix adenocarcinoma (HeLa) cells, further incubated alone or in the presence of $\mathrm{ACh}$ (thus simulating a biological region with overexpressed ACh). We studied Doxo delivery from S4 by means of cell viability WST-1 assays and confocal microscopy by tracking Doxo-associated fluorescence. Figure $4 B$ shows the cell viability results after $24 \mathrm{~h}$. These experiments clearly indicated the reduction in viability of the HeLa cells treated with $\mathbf{S} 4$ in a medium that contained ACh ( $50 \%$ of cells were dead after $24 \mathrm{~h}$ ). We ascribed this effect to the ACh-induced opening of S4 nanoparticles with the subsequent Doxo release. In contrast, the cells treated with S4 in an ACh-free medium remained alive, which indicated that S4 nanoparticles were not toxic for HeLa cells in the absence of ACh. We also observed a clear S4 concentration-dependent decrease of living cells in the presence of ACh (see Figure SI-8).
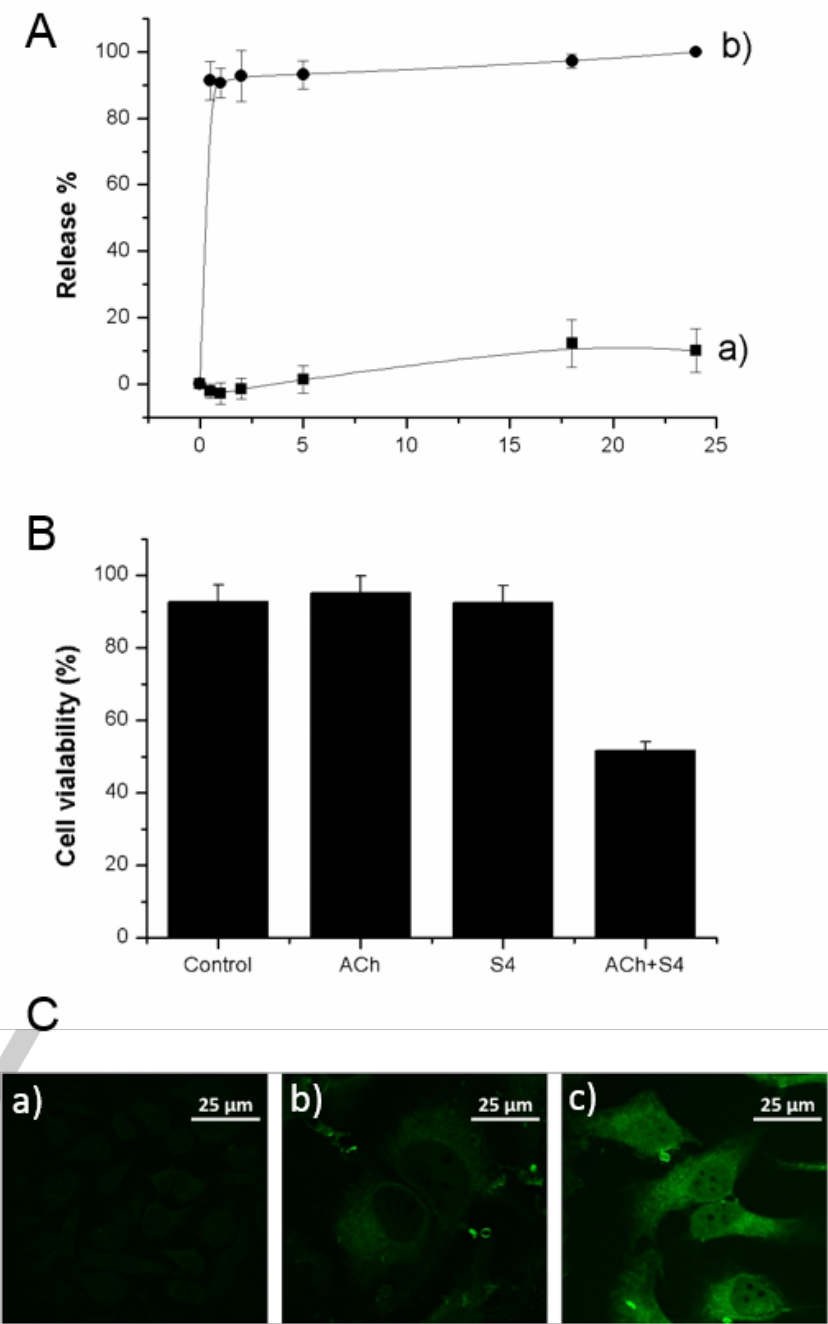

Figure 4. A) Kinetics of Doxo release from S4 $\left(0.9 \mathrm{mg} \cdot \mathrm{mL}^{-1}\right)$ in water at $\mathrm{pH} 7.5$ (20 $\left.\mathrm{mM} \mathrm{Na}_{\mathrm{s}} \mathrm{SO}_{4}\right)$ in the absence (a) and presence (b) of ACh $(10 \mathrm{mM})$, estimated by measuring fluorescence at $557 \mathrm{~nm}\left(\lambda_{\text {exc }}=495 \mathrm{~nm}\right)$. B) Cell viability test for S4. Results plotted from left to right for the control experiment, incubation with ACh $(40 \mathrm{mM})$, incubation with $\mathrm{S} 4\left(100 \mu \mathrm{g} \cdot \mathrm{mL}^{-1}\right)$, and incubation with both $\mathrm{ACh}(40 \mathrm{mM})$ and $\mathbf{S} 4100\left(\mu \mathrm{g} \cdot \mathrm{mL}^{-1}\right)$. Error bars for three independent experiments. C) Controlled release of Doxo from S4 $\left(100 \mu \mathrm{g} \cdot \mathrm{mL}^{-}\right.$ ${ }^{1}$ ) in HeLa cells culture media examined by confocal microscopy for (a) the control experiment, (b) incubation with S4 and (c) incubation with S4 and ACh.

Furthermore, the confocal microscopy images of the HeLa cells (Figure 4C) incubated with S4 showed clear Doxo-related fluorescence (green) in the cellular cytosolic compartment. In contrast, we observed negligible fluorescence in the cells incubated with $\mathbf{S 4}$ in ACh-free media. This meant that the nanocarrier was unable to release its cargo under these conditions. Remarkably, despite the presence of a large amount 
of cellular metabolites and proteins in the cell media, which could have compromised the performance of $\mathbf{S 4}$, the results indicated optimal functional behavior for the nanoparticles that delivered the cargo in the presence of ACh.

In conclusion, we have designed, synthesized and characterized a new enzyme-controlled nanocarrier for AChtriggered cargo delivery. In particular, the functional capped solid is based on Janus-type nanoparticles functionalized with acetylcholinesterase on the Au-face and a supramolecular $\mathrm{pH}$ responsive nanovalve on the MS surface. In the presence of ACh, the acetylcholinesterase enzyme hydrolyses the neurotransmitter and induces the dethreading of the nanovalve and cargo release. We observed fast cargo delivery kinetics (less than $5 \mathrm{~min}$ ) and a selective response to ACh among other neurotransmitters tested. The nanocarrier responded to $\mathrm{ACh}$ concentrations higher than $10 \mu \mathrm{M}$, which is below the ACh blood levels and within the range of concentrations found in neuromuscular junctions and in the striatum, the target region for PD drugs. The capped Janus nanoparticles displayed selective ACh-dependent cargo delivery even in a biological complex medium (HeLa cells). If we bear in mind the key role played by ACh and its relation with PD and other nervous system diseases, we believe that these findings could help design new therapeutic strategies. We also expect the possibility of combining different molecular gates on the MS face with distinct enzyme-based effectors on the Au surface to inspire the development of new advanced delivery systems that could selectively deliver their cargo in the presence of target small molecules of biological importance.

\section{Acknowledgments}

A. Llopis-Lorente is grateful to "La Caixa" Banking Foundation for his PhD fellowship. The authors are gratitude to the Spanish Government (MINECO Projects MAT2012-38429-C04-01, MAT2015-64139-C4-1, CTQ2014-58989-P and CTQ201571936-REDT) and the Generalitat Valencia (Project PROMETEOII/2014/047) for support. The Comunidad de Madrid (S2013/MIT-3029, Programme NANOAVANSENS) is also gratefully acknowledged.

Keywords: Janus nanoparticles $\bullet$ acetylcholine $\bullet$ nanodevice $\bullet$ controlled release $\bullet$ gated mesoporous materials

[1] a) C. Gotti, F. Clementi, Prog. Neurobiol. 2004, 74, 363-396; b) J. Lindstrom, Mol. Neurobiol. 1997, 15, 193-222; c) L. Descarries, V. Gisiger, M. Steriade, Prog. Neurobiol. 1997, 53, 603-625.

[2] L. Leblond, C. Beaufort, F. Delerue, T. P. Durkin, Behav. Brain Res. 2002, 128, 91-102; b) C. L. Nelson, J. A. Burk, J. P. Bruno, M. Sarter, Psychopharmacology (Berl) 2002, 161, 168-79; c) M. E. Hasselmo, J. M. Bower, Trends Neurosci. 1993, 16, 218-22; d) G. Pepeu, M. G. Giovannini, Learn. Mem. 2004. 11, 21-27.

[3] a) P. Calabresi, B. Picconi, L. Parnetti, M. Di Filippo, Lancet Neurol. 2006, 5, 974-983; b) G. Ehrenstein, Z. Galdzicki, G. D. Lange, Biophys. J. 1997, 73, 1276-1280; c) M. Reale, F. de Angelis, M. di Nicola, E. Capello, M. di loia, G. de Luca, A. Lugaresi, A. M. Tata, Int. J. Mol. Sci. 2012, 13, 12656-12664; d) R. S. Brett, J. H. Schmidt, J. S. Cage, S. A Schartel, P. J. Poppers, J. Am. Soc. Anesthesiol. 1987, 66, 837-838; e)
B. Picconi, E. Passino, C. Sgobio, P. Bonsi, I. Barone, V. Ghiglieri, A. Pisani, G. Bernardi, M. Ammassari-Teule, P. Calabresi, Neurobiol. Dis. 2006, 22, 143-52.

[4] a) A. Pisani, G. Bernardi, J. Ding, D. J. Surmeier, Trends Neurosci. 2007, 30, 545-553; b) T. Aosaki, M. Miura, T. Suzuki, K. Nishimura, M Masuda, Geriatr. Gerontol. Int. 2010, 10, S148-S157.

[5] a) A. D. Mosley, D. S. Romaine, The $A$ to $Z$ of Parkinson's Disease Checkmark Books, 2007; b) M. Guttman, S. J. Kish, Y. Furukawa, Can Med. Assoc. J. 2003, 168, 293-301.

[6] B. S. Connolly, A. E. Lang, JAMA 2014, 311, 1670-1683.

[7] S. Fahn, D. Oakes, I. Shoulson, K. Kieburtz, A. Rudolph, A. Lang, C. W. Olanow, C. Tanner, K. Marek, P. S. Group, N. Engl. J. Med. 2004, 351, 2498-2508.

[8] a) P. Jenner, Neurology 2002, 58, S1-S8; b) F. Stocchi, CNS Drugs 1998, 10, 159-170.

[9] S. Takahashi, H. Tohgi, H. Yonezawa, S. Obara, E. Yamazaki, J. Neurol. Sci. 1999, 167, 56-61.

[10] a) C. W. Olanow, Y. Agid, Y. Mizuno, Mov. Disord. 2005, 20, 643-644; b) O. Rascol, P. Payoux, F. Ory, J. J. Ferreira, C. Brefel-Courbon, J.-L. Montastruc, Ann. Neurol. 2003, 53(S3), S3-S15; c) E. Melamed, D Offen, A. Shirvan, I. Ziv, J. Neurol. 2000, 247, 135-139; d) T. Muller, H. Hefter, R. Hueber, W. Jost, K. Leenders, P. Odin, J. Schwarz, J. Neurol. 2004, 251, 44-46; e) T. López, J. L. Bata-García, D. Esquivel, E. OrtizIslas, R. Gonzalez, J. Ascencio, P. Quintana, G. Oskam, F. J. ÁlvarezCervera, F. J. Heredia-López, et al., Int. J. Nanomedicine 2011, 6, 1931.; f) T. López, D. Esquivel, G. Mendoza-Díaz, E. Ortiz-Islas, R. D. González, O. Novaro, Mater. Lett. 2015, 161, 160-163.

[11] a) E. Aznar, M. Oroval, L. Pascual, J. R. Murguía, R. Martínez-Máñez, F. Sancenón, Chem. Rev. 2016, 116, 561-718; b) S. Giret, M. Wong Chi Man, C. Carcel, Chem. Eur. J. 2015, 21, 13850-13865; c) M. ValletRegí, F. Balas, D. Arcos, Angew. Chem. Int. Ed. 2007, 46, 7548-7558 d) K. T. Kim, S. A. Meeuwissen, R. J. M. Nolte, J. C. M. van Hest Nanoscale 2010, 2, 844-858; e) G. Bao, S. Mitragotri, S. Tong, Annu. Rev. Biomed. Eng. 2013, 15, 253-282; f) S. Mura, J. Nicolas, P Couvreur, Nat. Mater. 2013, 12, 991-1003; g) S.-H. Wu, Y. Hung, C.-Y Mou, Chem. Commun. 2011, 47, 9972-9985.

[12] a) F. Tang, L. Li, D. Chen, Adv. Mater. 2012, 24, 1504-34; b) Z. Li, J. C. Barnes, A. Bosoy, J. F. Stoddart, J. I. Zink, Chem. Soc. Rev. 2012, 41, 2590-2605; c) D. Tarn, C. E. Ashley, M. Xue, E. C. Carnes, J. I. Zink, C J. Brinker, Acc. Chem. Res. 2013, 46, 792-801; d) Y. Zhao, J. L. Vivero-Escoto, I. I. Slowing, B.G. Trewyn, V. S.-Y. Lin, Expert Opin Drug Deliv. 2010, 7, 1013-1029; e) C. Argyo, V. Weiss, C. Bräuchle, T. Bein, Chem. Mater. 2014, 26, 435-451; f) Y.-W Yang, Y.-L. Sun, N Song, Acc. Chem. Res. 2014, 47, 1950-1960; g) A. Popat, S. B. Hartono, F. Stahr, J. Liu, S. Z. Qiao, G. Qing Lu, Nanoscale 2011, 3 2801-2818

[13] a) T. M. Guardado-Alvarez, L. Sudha Devi, M. M. Russell, B. J. Schwartz, J. I. Zink, J. Am. Chem. Soc. 2013, 135, 14000-14003; b) F. Sancenón, L. Pascual, M. Oroval, E. Aznar, R. Martínez-Máñez, ChemistryOpen, 2015, 4, 418-437; c) E. Yu, I. Galiana, R. MartínezMáñez, P. Stroeve, M. D. Marcos, E. Aznar, F. Sancenón, J. R. Murguía, P. Amorós, Colloids Surf. B. 2015, 135, 652-660; d) A. Baeza, E. Guisasola, E. Ruiz-Hernández, M. Vallet-Regí, Chem. Mater. 2012, 24, 517-524; e) A. Bernardos, E. Aznar, M. D. Marcos, R. MartínezMáñez, F. Sancenón, J. Soto, J. M. Barat, P. Amorós, Angew. Chem. Int. Ed. 2009, 121, 5998-6001; f) Z. Zhang, D. Balogh, F. Wang, S. Y Sung, R. Nechushtai, I. Willner, E. Sciences, ACS nano 2013, 7, 84558468; g) S. El Sayed, C. Giménez, E. Aznar, R. Martínez-Máñez, F Sancenón, M. Licchelli, Org. Biomol. Chem. 2015, 13, 1017-1021; h) A. Bansal, Y. Zhang, Acc. Chem. Res. 2014, 47, 3052-3060; i) V. Z. Ozalp, F. Eyidogan, H. A. Oktem, Pharmaceuticals 2011, 4, 1137-1157; j) R. de la Rica, D. Aili, M. M. Stevens, Adv. Drug Delivery Rev. 2012, 64, 967-978, k) K. C.-F. Leung, C. P. Chak, C.-M. Lo, W.-Y Wong, S. Xuan, C. H. K. Cheng, Chem.-Asian J. 2009, 4, 364-381.

[14] a) R. Villalonga, P. Díez, A. Sánchez, E. Aznar, R. Martínez-Máñez, J. M. Pingarrón, Chem. Eur. J. 2013, 19, 7889-7894; b) P. Díez, A. 
Sánchez, M. Gamella, P. Martínez-Ruíz, E. Aznar, C. De La Torre, J. R. Murguía, R. Martínez-Máñez, R. Villalonga, J. M. Pingarrón, J. Am. Chem. Soc. 2014, 136, 9116-9123.

[15] a) C. Coll, A. Bernardos, R. Martínez-Máñez, F. Sancenón, Acc. Chem. Res. 2013, 46, 339-349; b) E. Aznar, R. Martinez-Manez, F. Sancenon Expert Opin. Drug Deliv. 2009, 6, 643-655; c) A. Ultimo, C. Giménez, P. Bartovsky, E. Aznar, F. Sancenón, M. D. Marcos, P. Amorós, A. R. Bernardo, R. Martínez-Máñez, A. M. Jiménez-Lara, J. R. Murguía Chem. Eur. J. 2016, 22, 1582-1586; d) L. Pascual, I. Baroja, E. Aznar, F. Sancenón, M. D. Marcos, J. R. Murguía, P. Amorós, K. Rurack, R. Martínez-Máñez, Chem. Commun. 2015, 51, 1414-1416; e) C. Giménez, E. Climent, E. Aznar, R. Martínez-Máñez, F. Sancenón, M. D. Marcos, P. Amorós, K. Rurack, Angew. Chem. Int. Ed. 2014, 53, 12629-12633.

[16] a) J.A. Turkevich, Discuss. Faraday Soc. 1951, 11, 55-75; b) G.Frens, Nature 1973, 241, 20-22

[17] a) L. Gómez, H.L. Ramírez, M.L. Villalonga, J. Hernández, R. Villalonga, Enzyme Microb. Technol. 2006, 38, 22-27; b) B. Chico, C. Camacho, M. Pérez, M.A. Longo, M.A. Sanromán, J.M. Pingarrón, R. Villalonga, J. Electroanal. Chem. 2009, 629, 126-132.

[18] A. Sánchez, P. Díez, P. Martínez-Ruíz, R. Villalonga, J. M. Pingarrón, Electrochem. Commun. 2013, 30, 51-54.

[19] G. Jerez, G. Kaufman, M. Prystai, S. Schenkeveld, K. K. Donkor, J. Sep. Sci. 2009, 32, 1087-1095.

[20] S. Lin, C.-C. Liu, T.-C. Chou, Biosens. Bioelectron. 2004, 20, 9-14.

[21] a) E. S. Vizi, A. Fekete, R. Karoly, A. Mike, Br. J. Pharmacol. 2010, 160, 785-809; b) A. Schena, K. Johnsson, Angew. Chem. Int. Ed. 2014, 53 1302-1305; c) Y. Zhou, L.-L.Tan, Q.-L. Li, X-L. Qiu, A.-D. Qi, Y. Tao, Y.-W. Yang, Chem. Eur. J. 2014, 20, 2998-3004.

[22] a) R. Hassler, P. Haug, C. Nitsch, J. S. Kim, K. Paik, J. Neurochem. 1982, 38, 1087-1098; b) M. H. Sethy, V. H.; Van Woert, Nature 1974 251, 529-530.

[23] Z. Batool, S. Sadir, L. Liaquat, S. Tabassum, S. Madiha, S. Rafiq, S. Tariq, T. S. Batool, S, Saleem, Fizza Naqvi et. al., Brain Res. Bull. 2016, $120,63-74$. 
Layout 1:

\section{COMMUNICATION}

We prepared and characterized Janus Au-mesoporous silica nanoparticles functionalized with

acetylcholinesterase on the Au face and with supramolecular $\beta$ cyclodextrin:benzimidazole inclusion complexes as caps on the mesoporous silica face. The nanodevice is able to selectively deliver cargo in the presence of acetylcholine via enzyme-mediated acetylcholine hydrolysis, locally lowering $\mathrm{pH}$ and opening the supramolecular gate.

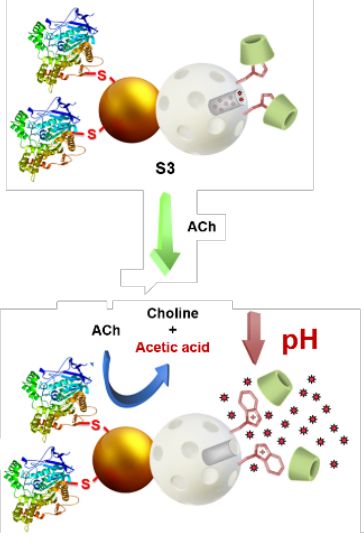

A. Llopis Lorente, P. Díez, C. de la Torre, A. Sánchez, F. Sancenón, $A$ Aznar, M. D. Marcos, P. Martínez-Ruíz, R. Martínez-Mañez*, V. Villalonga.*

Page No. - Page No.

Enzyme-Controlled Nanodevice for Acetylcholine-Triggered Cargo Delivery Based on Janus AuMesoporous Silica Nanoparticles 